\title{
Effect of Single Vs Two Injections of Platelet-Rich Plasma (PRP) In Symptomatic Patients with Knee Osteoarthritis
}

Lovjot Singh*, Rohit Sharma, Ramneet, Umesh Yadav, Amit Dhaiya, Abhishek, Amit, Meet kamal singh and Surinder Jaiswal

Pandit bhagwat dayal sharma university of health sciences, PGIMS Rohtak, India

Submission: October 19, 2020; Published: November 04, 2020

*Corresponding author: Dr. Lovjot Singh, Pandit bhagwat dayal sharma university of health sciences, PGIMS Rohtak, India

Abstract

Aims and Objective: To study effect of intra-articular injection of platlet rich plasma (PRP) in patients with symptomatic knee osteoarthritis $(\mathrm{OA})$ and to compare effect of single v/s two injections of plasma rich platelets(PRP) in osteoarthritis(OA) knee

Material and Methods: We prospectively followed 60 patients with symptomatic knee Osteoarthritis of grade 1-3 as per Kellgren-Lawrence classification based on x-ray findings. The standard radiographic evaluation included a standing AP and lateral view of the knees. Group 1 - 30 patients were given 1 intra-articular injection of Autologous PRP and followed up for a period of 1year. Group 2 - 30 patients were given 2 intraarticular injection of Autologous PRP 2 weeks apart and followed up for a period of 1year. The standard blood investigations before treatment were $\mathrm{CBC}$, Coagulation profile and test for transmittable diseases (HIV,HCV,HbsAg).

Conclusion: We conclude that intra- articular injection of Autologous PrP is an acceptable method to relieve pain in first three stages of O.A. Due to Autologous nature of PRP there are very less chances of complication, thus we recommended intra-articular PRP injection is a simple, minimally invasive, safe and effective method which can be used for the treatment of osteoarthritis of knee. 2 injections of PRP given at 2 weeks apart gives better relief from pain based on VAS and KOOS score at 3 months follow up but data was not significant comparing single vs two injections of prp at follow up of 6months and 12 months.

\section{Introduction}

Hyaline cartilage, known for its unique properties, enables almost frictionless joint movement and protects the underlying bone from excessive load and trauma by dissipating the forces produced during movement. However, cartilage has limited intrinsic healing potential because it is a vascular and has a few specialized cells with a low mitotic activity [1]. Once the cartilage is injured, it gradually degenerates, leading to osteoarthritis (OA). The name osteoarthritis comes from Greek word 'osteo' = 'of the bone', 'arthro' = 'joint' and 'itis' = 'inflammation' [2]. The disease process not only affects the articular cartilage, but involves the entire joint, including the subchondral bone, ligaments, capsule, synovial membrane, and periarticular muscles. In severe conditions, when knee joints completely lose cartilage, the periarticular bone and soft tissue structures would start to change and this may cause joint pain, swelling, misshapenness, and disability $[3,4]$.

The social impact of degenerative diseases such as articular cartilage pathology and osteoarthritis (OA) is steadily increasing, because of the continued rise in the mean age of the active population [5]. As a consequence of the aging process, the number of people with Knee Osteoarthritis is expected to increase in the next decades and it is affecting $12.1 \%$ of population from $25-74$ years old and it is the leading cause of physical disability in people older than 65 years [6-8]. In Recent research evidence, knowledge increases regarding the pathogenesis and natural history of $\mathrm{OA}$, particularly the metabolically active role of the disease and the process of remodelling and repair of damaged tissue. Current thinking is that it may be possible to arrest the progress of, and potentially even reverse, the disease [9].

\section{Primary osteoarthritis [10]}

Primary OA results from abnormal stresses on weight-bearing joints or normal stresses operating on weakened joints.

Secondary osteoarthritis [2]

Secondary OA results from chronic or sudden injury to a joint, infective pathology etc. It can occur in any joint. 


\section{Orthopedics and Rheumatology Open Access Journal (OROAJ)}

\section{Kellgren-Lawrence Grading System for OA, 1957 [11]}

(This is radiological assessment in which x-ray of both knees AP view in standing position are taken). (Figure 2)

Grade 0: Normal, no features.

Grade 1: Questionable presence of osteophytes/questionable presence of joint space narrowing / both.

Grade 2: Definite presence of osteophytes with possible joint space narrowing or definite mild joint space narrowing.

Grade 3: Definite moderate joint space narrowing (at least $50 \%)$ Osteophytes usually present, Cysts/sclerosis may be present.

Grade 4: Severe joint space narrowing with subchondral bone sclerosis and possible deformity of bone ends.

In osteoarthritis, there is increased blood flow and other changes that develop in the subchondral layer, subchondral sclerosis (increased bone density), subchondral cysts (fluid-filled sacs which extrude from the joint), and increased pressure within the bone -- all of which may cause osteoarthritis pain. There can be thickening of the joint capsule and the formation of osteophytes that may cause pain. There can be increased thickness of the synovium and mild inflammation at this site that causes pain (Figure 1).
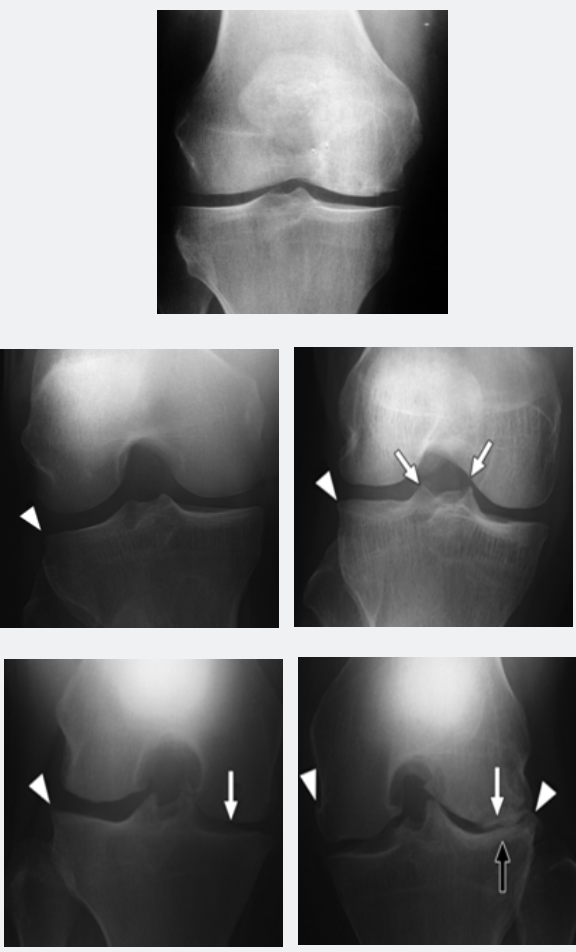

Figure 1: Kellgren-Lawrence Grading System for OA.

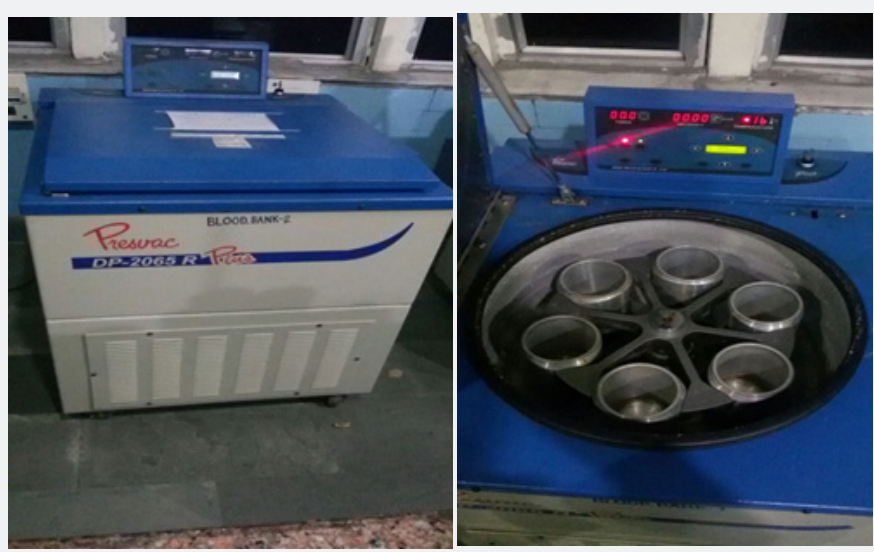

Figure 2: Presvac Cryofuge. 


\section{Treatment}

\section{Autologous Intra-articular PRP Injection}

Platelet-rich plasma (PRP) therapy involves injecting a solution of the patient's own concentrated blood components (especially platelets) into their knee: the aim is to promote cartilage repair and relieve symptoms. Platelet Rich Plasma (PRP) injection, a novel approach, gives significant improvement in osteoarthritis due to the presence of autogenous growth factors and attract the Mesenchymal stem cells to start the chondroprotective and chondroregenerative potential in knee joint. Mesenchymal stem cells (MSCs) are the focus for the development of many cellbased therapies for a diverse array of diseases and are a subset of nonhematopoietic adult stem cells that originate from the mesoderm and exist in almost all adult tissues [12].

PRP can be defined as the volume of the plasma fraction from autologous blood with platelet concentration above baseline count $(200,000$ platelets per/microLitre). The rationale for the use of PRP is to stimulate the natural healing cascade and tissue regeneration by a "supraphysiologic" release of platelet-derived factors directly at the site of treatment. The term "activation" refers to two key processes within GFRP preparations that may be initiated: (1) degranulation of platelets to release granules containing growth factors and (2) fibrinogen cleavage to initiate matrix formation.

Accordingly, platelet activation can be achieved by the following 3 mechanisms: i. Addition of calcium chloride and thrombin,

ii. Freeze/thaw cycles, and

iii. Direct exposure to collagen in vivo.

PRP is a simple, low cost and minimally invasive method to obtain a high concentrate of autologous GFs in physiological proportions, which can be easily and safely placed directly into the lesion site. Moreover, the risk of allergy or infection is negligible, due to the autologous nature of the platelet extract. Platelet-rich plasma (PRP) is one therapeutic application with promising preliminary clinical results.

\section{Material and Methods}

We prospectively followed 60 patients with symptomatic knee Osteoarthritis of grade 1-3 as per Kellgren-Lawrence classification based on x-ray findings. The standard radiographic evaluation included a standing AP and lateral view of the knees.

Group 1 - 30 patients were given 1 intra-articular injection of Autologous PRP and followed up for a period of 1year.

Group 2 - 30 patients were given 2 intra-articular injection of Autologous PRP 2 weeks apart and followed up for a period of 1year

The standard blood investigations before treatment were $\mathrm{CBC}$, Coagulation profile and test for transmittable diseases (HIV,HCV,HbsAg) (Table 1).

Table 1: kellgren-lawrence classification.

\begin{tabular}{|c|c|}
\hline \multicolumn{2}{|c|}{ KELLGREN-LAWRENCE CLASSIFICATION } \\
\hline GRADE & DESCRIPTION \\
\hline 0 & Normal \\
\hline 1 & Doubtful narrowing of joint space and possible osteophytic lipping \\
\hline 2 & Definite osteophytes and possible narrowing of joint space \\
\hline 3 & Large osteophytes, marked narrowing of joint space, severe sclerosis, and definite deformity of bone ends \\
\hline 4 &
\end{tabular}

\section{Inclusion Criteria}

i. Age between 30 and 60 years, body mass index $<30$, normal results for complete blood count and coagulation control, minimum follow-up of 6 months.

ii. Patients with symptomatic osteoarthritic knees(Kellgren-Lawrence grade 1-3 based on radiographic findings)

iii. Patients with severe pain and under anti-inflammatory treatment without improvement $>3$ months.

iv. Patients with stable knees, normal tibiofemoral alignment, or patellofemoral tracking.

v. Patients with or without previous cartilage shaving and microfracture (other interventions were excluded).

vi. Patients who gave consent for treatment with plateletrich plasma per our protocol.

\section{Exclusion Criteria}

i. Patients with blood diseases, systemic metabolic, immunodeficiency, hepatitis B or C, HIV-positive status, infection and septicemia , local infection.

ii. Patients with advanced and tricompartmental osteoarthritis, rheumatoid or polyarticular arthritis, symptomatic hip osteoarthritis, or symptomatic contralateral knee osteoarthritis. 


\section{Orthopedics and Rheumatology Open Access Journal (OROAJ)}

iii. Significant joint swelling or clinical signs of acute inflammation( possible infection or infection )

iv. Varus-Valgus malalignment above $5^{\circ}$, patellofemoral tracking or untreated instability, and total or subtotal meniscectomy $(>2 / 3$ excised).

v. Pretreatment blood platelets value $25 \%$ below the reference value or alcoholism, smoking, drugs.

vi. Treatment with corticosteroids within 3 months or medication within 7 days that could interfere with platelet aggregation.

\section{Platelet Rich Plasma: Contraindications}

\section{Absolute Contraindications:}

- Platelet dysfunction syndrome

- $\quad$ Critical thrombocytopenia
- Hemodynamic instability

- $\quad$ Septicemia

- Local infection at the site of the procedure

- $\quad$ Patient unwilling to accept risks

Relative Contraindications:

- $\quad$ Consistent use of NSAIDs within 48 hours of procedure

- $\quad$ Corticosteroid injection at treatment site within 1 month

- $\quad$ Systemic use of corticosteroids within 2 weeks

- $\quad$ Recent fever or illness

- Cancer- especially hematopoietic or of bone

- $\quad \mathrm{HGB}<10 \mathrm{~g} / \mathrm{dl}$

- $\quad$ Platelet count $<105 / \mathrm{ul}$

\section{Technique}

\section{Preparation of PRP}

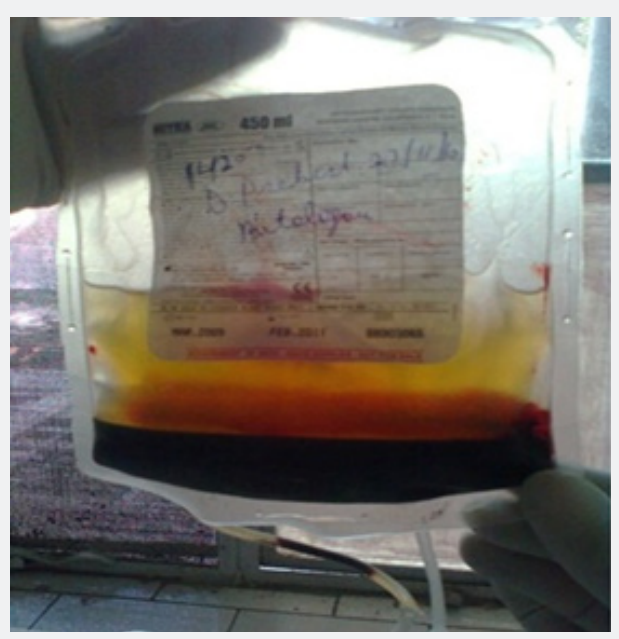

Figure 3: RBC concentrate at the bottom and plasma above (After 1st centrifuge).

The PRP required for injection was prepared and provided by the Department of Transfusion Medicine, SGRDIMSR. About $100 \mathrm{~mL}$ of venous blood was drawn under aseptic precautions from the anticubital vein. The blood was collected in an adult double bag with CPD-A1 (citrate phosphate dextrose and adenine) as an anticoagulant. This bag underwent two centrifugations (the first at 1,800 rpm for $15 \mathrm{~min}$ to separate erythrocytes, and a second at $3,500 \mathrm{rpm}$ for $10 \mathrm{~min}$ to concentrate platelets) to produce about $15 \mathrm{ml}$ of PRP. The final PRP was taken for injection in a $10-\mathrm{mL}$ syringe (approximately $8 \mathrm{~mL}$ per knee) and sample was sent to lab for assessment of platelet count (Figures $2 \& 3$ ).

\section{Interventional Procedure:}

Group 1 - 30 patients were given 1 intra-articular injection of
Autologous PRP and followed up for a period of 1year

Group 2 - 30 patients were given 2 intra-articular injection of Autologous PRP 2 weeks apart and followed up for a period of 1year

Under aseptic conditions, $8 \mathrm{~mL}$ of plasma concentrate was injected supero-medially into the knee joint with an 18-gauge needle. At the end of procedure, the patient was encouraged to bend and extend the knee a few times, to allow the PRP to distribute itself throughout the joint before becoming gel. After the injection, the patients were sent home with instructions on limiting the use of the leg and not to use nonsteroidal medication but to use cold therapy for pain for at least 5 days 


\section{Evaluation of Results}

Results were evaluated according to the Knee injury and Osteoarthritis Outcome Score (KOOS) before treatment, and at 3 months, 6 months, and at 1year after treatment. Patients will also be evaluated for pain by visual analog scale. Data will be evaluated statistically.

Table 2: VAS.

\section{VAS}

Before the injection, the pain was considered at $100 \mathrm{~mm}$ in all patients and at every follow up; patient was asked to mark a point on the line to explain how much of pain relief he/she is having (Table 2).

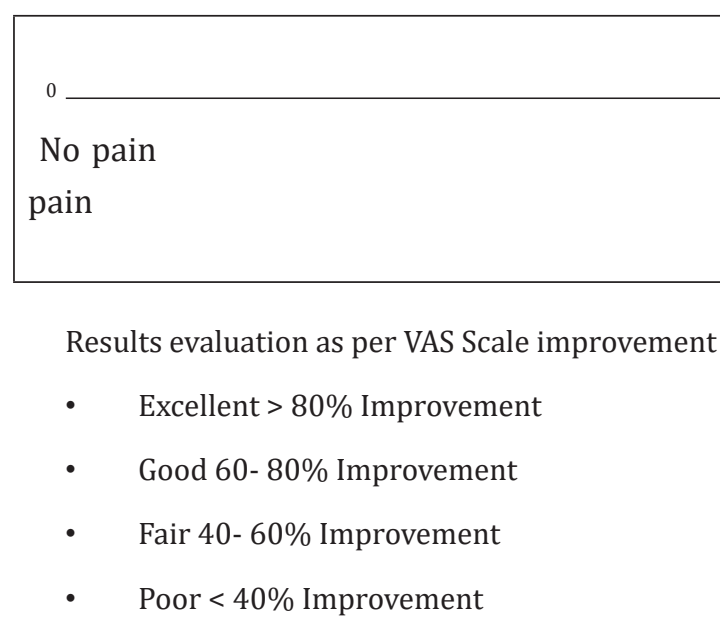

\section{Knee Injury and Osteoarthritis Outcome Score (KOOS)}

The Knee Injury and Osteoarthritis Outcome Score (KOOS) is a questionnaire designed to assess short and long-term patient-relevant outcomes following knee injury. The KOOS is self-administered and assesses five outcomes: pain, symptoms, activities of daily living, sport and recreation function, and kneerelated quality of life. The KOOS meets basic criteria of outcome measures and can be used to evaluate the course of knee injury and treatment outcome. KOOS is patient-administered, the format is user-friendly, and it takes about 10 minutes to fill out.

\section{Scoring Instructions}

The KOOS's five patient-relevant dimensions are scored separately: Pain (nine items); Symptoms (seven items); ADL Function (17 items); Sport and Recreation Function (five items); Quality of Life (four items). A Likert scale is used, and all items have five possible answer options scored from 0 (No problems) to 4 (Extreme problems) and each of the five scores is calculated as the sum of the items included.

\section{Interpretation of scores}

Scores are transformed to a 0-100 scale, with zero representing extreme knee problems and 100 representing no knee problems as common in orthopaedic scales and generic measures. Scores between 0 and 100 represent the percentage of total possible score achieved.

\section{Observations}

This study was conducted in Orthopaedics Department of Sri Guru Ram Das Medical college and Hospital, Amritsar on 60 patients with symptomatic knee Osteoarthritis of grade 1-3 as per Kellgren-Lawrence classification based on x-ray findings. The standard radiographic evaluation included was standing AP and lateral view of the knees.

Group 1 - 30 patients were given 1 intra-articular injection of Autologous PRP and followed up for a period of 1year.

Group 2 - 30 patients were given 2 intra-articular injection of Autologous PRP 2 weeks apart and followed up for a period of 1year.

The participants were followed up on a regular basis with clinical examinations and functional evaluations for pain relief as per VAS scale and KOOS score. All examinations were taken at 3 month, 6 months, and 12 months.

Following observations were made at different follow ups:

\section{AGE}

The youngest patient in Group 1 of this study was 40 years and oldest was of 60 years and in Group 2 youngest was 42 years and oldest 59 years old. Average age of Group 1 was 51.7 years and of Group 2 was 50.33 years.

$60 \%$ of patients in Group 1 were in 51-60 age group and 40\% were between 40-50 age group. In Group 2, 50\% were between 51-60 and 50\% between 40-50 age group (Table 3) (Graph 1).

Table 3: Age wise distribution of cases in both groups.

\begin{tabular}{|c|c|c|c|c|c|}
\hline \multirow{2}{*}{ Age (years) } & \multicolumn{2}{|c|}{ Group 1 } & \multicolumn{2}{c|}{ Group 2 } & Total \\
\cline { 2 - 6 } & N & $\%$ & N & $\%$ & \\
\hline $40-50$ & 12 & 40.0 & 15 & 50.0 & 27 \\
\hline $51-60$ & 18 & 60.0 & 15 & 50.0 & 33 \\
\hline Total & 30 & 100.0 & 30 & 100.0 & 60 \\
\hline
\end{tabular}

$x^{2}=0.606 ; d f=1 ; p=0.436 ;$ Not significant 


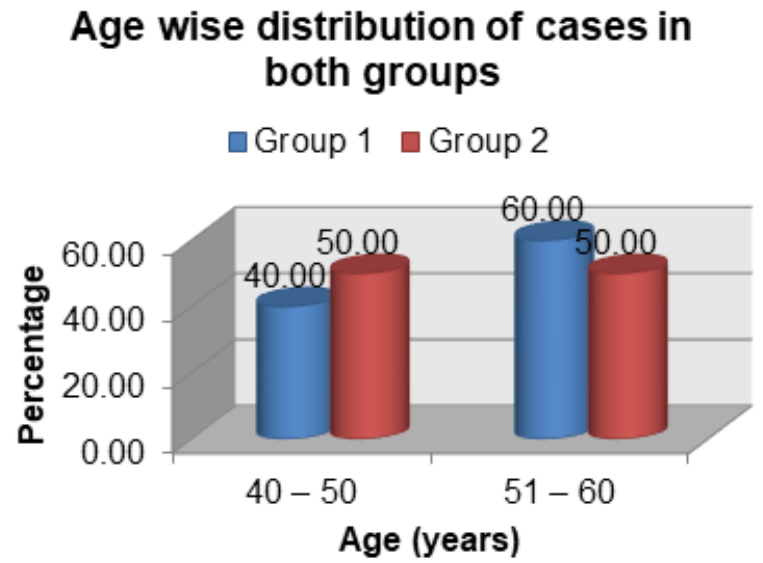

Graph 1

SEX

In our study females outnumbered males in presenting with pain due to knee OA both in Group 1 and 2. 18 (60\%) patients were female and $12(40 \%)$ patients were male in Group 1 and 17 $(56.7 \%)$ patients were female and $13(43.3 \%)$ were male in Group 2. Female to male ratio was 6:4 in Group 1 and 1.3:1 in Group 2 (Table 4) (Graph 2).

Table 4: Sex wise distribution of cases in both groups.

\begin{tabular}{|c|c|c|c|c|c|}
\hline \multirow{2}{*}{ Sex } & \multicolumn{2}{|c|}{ Group 1 } & \multicolumn{2}{|c|}{ Group 2 } & \multirow{2}{*}{ Total } \\
\cline { 2 - 6 } & N & \% & N & 56.7 & 35 \\
\hline F & 18 & 60.0 & 17 & 43.3 & 25 \\
\hline M & 12 & 40.0 & 30 & 100.0 & 60 \\
\hline Total & 30 & 100.0 & 30 & \\
\hline
\end{tabular}

$x^{2}=0.069 d f=1 ; p=0.793 ;$ Not significant

\section{Sex wise distribution of cases in both groups}

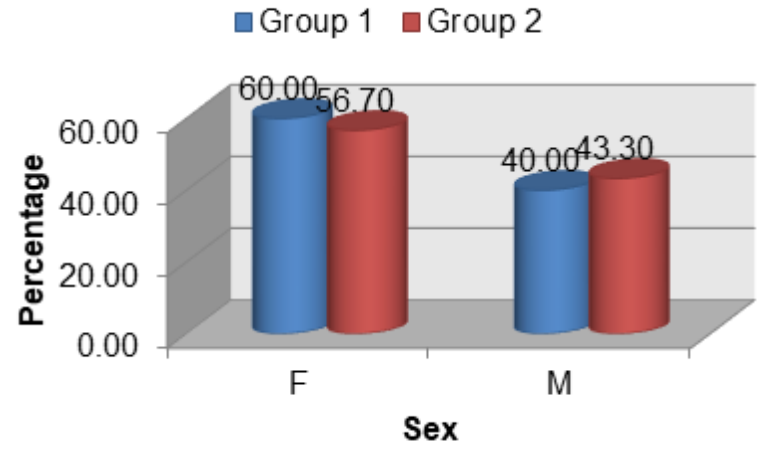

Graph 2

\section{Side Involved}

Ratio of side of limb involvement from left to right was 7:8 both in Group 1 and 2. As per there is no specific side predilection for knee osteoarthritis (Table 5) (Graph 3). 


\section{Affected side wise distribution of cases in both groups}

घroup 1 -Group 2
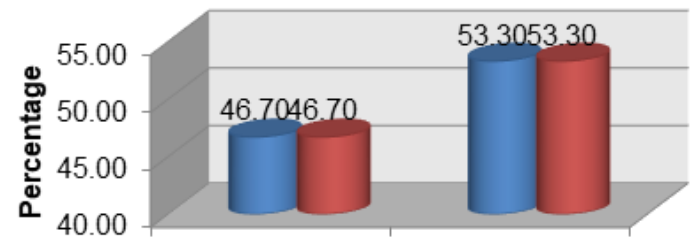

L

Side affected

\section{Graph 3}

Table 5: Affected side wise distribution of cases in both groups.

\begin{tabular}{|c|c|c|c|c|c|}
\hline \multirow{2}{*}{ Side affected } & \multicolumn{2}{|c|}{ Group 1} & \multicolumn{2}{|c|}{ Group 2} & \multirow{2}{*}{ Total } \\
\hline & $\mathbf{N}$ & $\%$ & $\mathbf{N}$ & $\%$ & \\
\hline $\mathrm{L}$ & 14 & 46.7 & 14 & 46.7 & 28 \\
\hline $\mathrm{R}$ & 16 & 53.3 & 16 & 53.3 & 32 \\
\hline Total & 30 & 100.0 & 30 & 100.0 & 60 \\
\hline
\end{tabular}

$x^{2}=0.000 \mathrm{df}=1 ; p=1.000 ;$ Not significant

Kellgren-Lawrence Grading for Osteoarthritis

The targeted study population with Kellgren-Lawrence Grade 1 , grade 2 and grade 3 were recruited in this study. In study 6
(20\%) patients of grade $1,16(53.3 \%)$ patients of grade 2 and $8(26.7 \%)$ patients of grade 3 were included in study both in Group 1 and 2 (Table 6) (Graph 4).

\section{Grade wise distribution of cases in both groups \\ घGroup 1 aroup 2

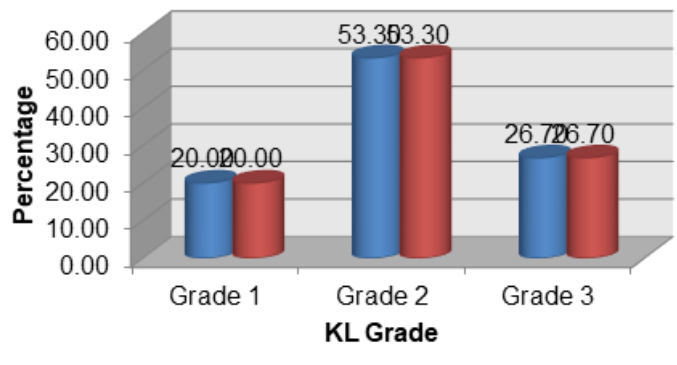

Graph 4

Table 6: Grade wise distribution of cases in both groups.

\begin{tabular}{|c|c|c|c|c|c|}
\hline \multirow{2}{*}{ KL Grade } & \multicolumn{2}{|c|}{ Group 1 } & \multicolumn{2}{|c|}{ Group 2 } & \multirow{2}{*}{ Total } \\
\cline { 2 - 6 } & $\mathbf{N}$ & \% & N & 20.0 & 12 \\
\hline 1 & 6 & 20.0 & 6 & 53.3 & 32 \\
\hline 2 & 16 & 53.3 & 16 & 26.7 & 16 \\
\hline 3 & 8 & 26.7 & 30 & 100.0 & 60 \\
\hline
\end{tabular}

$x^{2}=0.000 \mathrm{df}=2 ; p=1.000 ;$ Not significant 


\section{VAS Scores}

VAS score was considered as 100 in all the patients at the start of the study. After injecting the PrP at 3months, 6 months and 12 months interval patients were asked to mark a point for the level of pain on a straight unmarked line $100 \mathrm{~mm}$ long. Once the marking was done by a patient, it was measured with a measuring scale to know VAS score. Lesser the VAS score better was the pain relief.

In Group 1 at 3-month VAS score ranged from 15 to $30 \mathrm{~mm}$ and mean score of 21.67 and standard deviation of 5.47. Improvement in VAS score at 3 months from baseline was calculated which came out to be mean score of 78.33 and standard deviation of 5.47. In Group 2 at 3-month VAS score ranged from 5 to $15 \mathrm{~mm}$ and mean score of 9.83 and standard deviation of 3.07. Improvement in VAS score at 3 months from baseline was calculated which came out to be mean score of 90.17 and standard deviation of 3.07. In Group
1 at 6 months follow up VAS score ranged from 15 to $35 \mathrm{~mm}$ and mean score of 23.50 and standard deviation of 6.04 . At 6 months follow up improvement with mean score of 76.50 and standard deviation of 6.04 was noted. In Group 2 at 6-month VAS score ranged from 10 to $35 \mathrm{~mm}$ and mean score of 21.67 and standard deviation of 6.35. Improvement in VAS score at 6 months from baseline was calculated which came out to be mean score of 79.00 and standard deviation of 6.35 .

In Group 1 at 12 months follow up VAS score ranged from 35 to $55 \mathrm{~mm}$ and mean score of 41.17 and standard deviation of 5.52 . At 12 months follow up improvement was 58.83 and standard deviation of 5.52. In Group 2 at 12-month VAS score ranged from 30 to $50 \mathrm{~mm}$ and mean score of 39.50 and standard deviation of 5.78. Improvement in VAS score at 12 months from baseline was calculated which came out to be mean score of 60.50 and standard deviation of 5.78 (Graphs 5-7) (Tables 7-9).
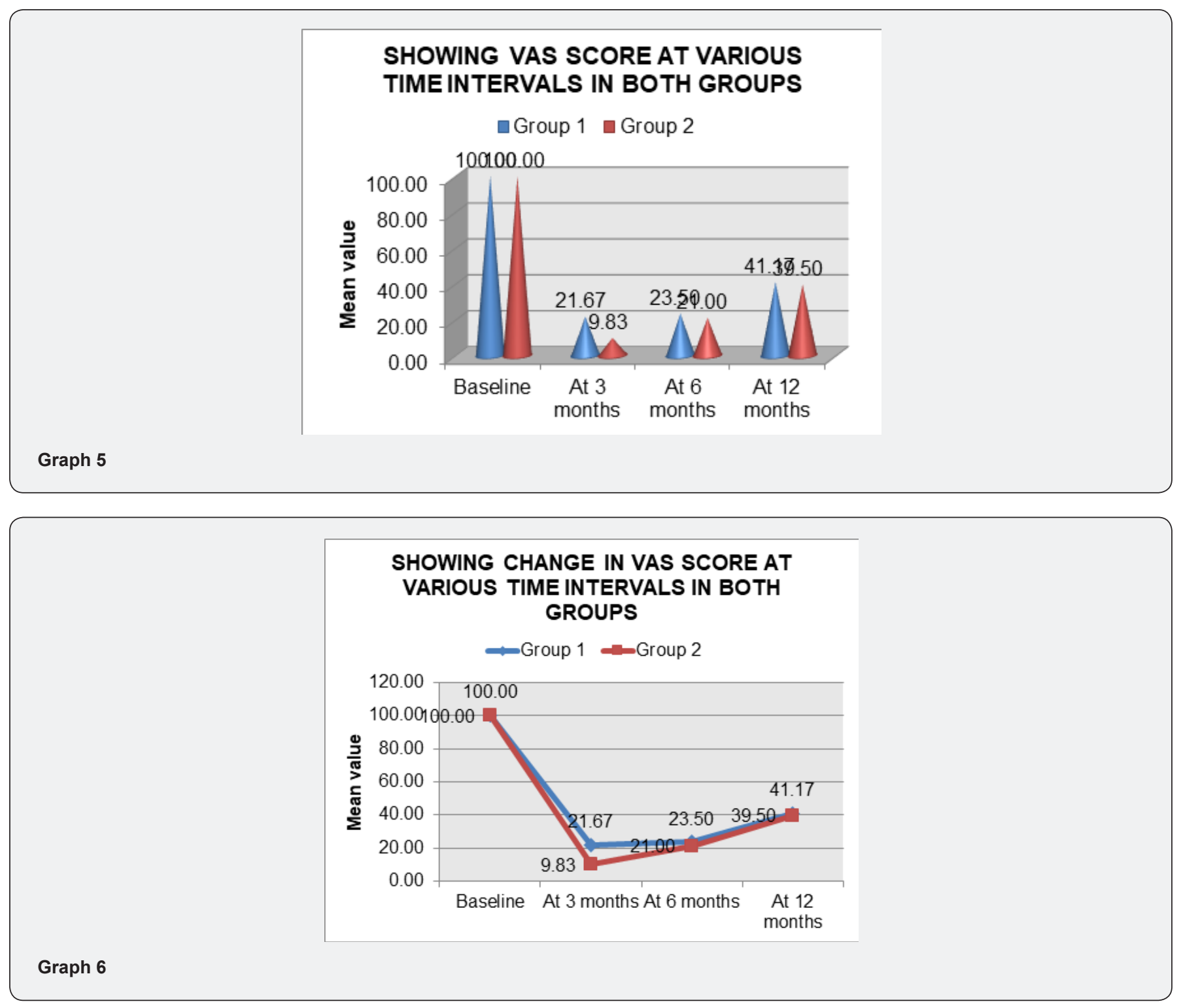


\section{SHOWING COMPARISON OF IMPROVEMENTIN VAS SCORE BETWEEN TWO GROUPS}

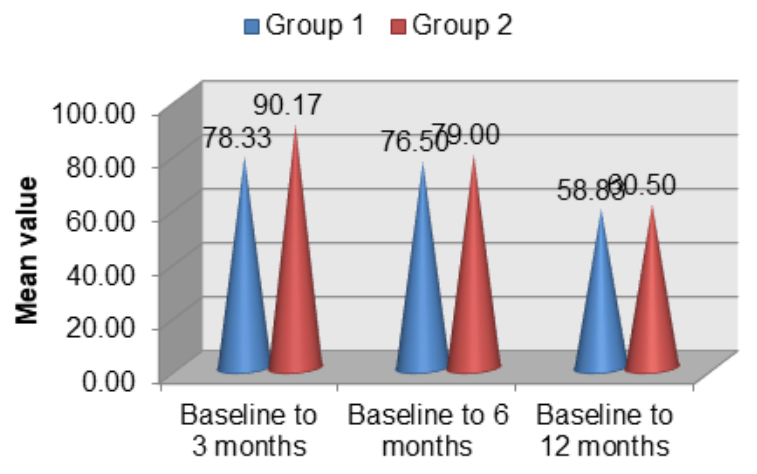

Graph 7

Table 7: Table Showing Vas Score at Various Time Intervals.

\begin{tabular}{|c|c|c|c|c|c|c|c|}
\hline \multirow{2}{*}{ Time } & \multicolumn{3}{|c|}{ Group 1 } & \multicolumn{3}{c|}{ Group 2 $^{*}$ P value $^{\sharp}$} \\
\cline { 2 - 8 } & Range & Mean & SD & Range & Mean & SD & - \\
\hline Baseline & $100-100$ & 100.00 & 0.00 & $100-100$ & 100.00 & 0.00 & 3.07 \\
\hline At 3 months & $15-30$ & 21.67 & 5.47 & $5-15$ & 9.83 & $<0.001^{* *}$ \\
\hline At 6 months & $15-35$ & 23.50 & 6.04 & $10-35$ & 21.00 & 6.35 & 0.124 \\
\hline At 12 months & $35-55$ & 41.17 & 5.52 & $30-50$ & 39.50 & 5.78 & 0.258 \\
\hline
\end{tabular}

\#Unpaired ' $t$ ' test; ** $p<0.001$; Highly significant

Table 8: Table Showing Change in Vas Score at Various Time Intervals.

\begin{tabular}{|c|c|c|c|c|c|c|c|c|}
\hline \multirow{2}{*}{ Time } & \multicolumn{3}{|c|}{ Group 1 } & \multicolumn{3}{c|}{ Group 2 } \\
\cline { 2 - 9 } & Mean & SD & Improvement & P value $^{*}$ & Mean & SD & Improvement $^{*}$ P value \\
\hline Baseline & 100.00 & 0.00 & - & - & 100.00 & 0.00 & - & - \\
\hline At 3 months & 21.67 & 5.47 & $78.33 \pm 5.47$ & $<0.001^{* *}$ & 9.83 & 3.07 & $90.17 \pm 3.07$ & $<0.001^{* *}$ \\
\hline At 6 months & 23.50 & 6.04 & $76.50 \pm 6.04$ & $<0.001^{* *}$ & 21.00 & 6.35 & $79.00 \pm 6.35$ & $<0.001^{* *}$ \\
\hline At 12 months & 41.17 & 5.52 & $58.83 \pm 5.52$ & $<0.001^{* *}$ & 39.50 & 5.78 & $60.50 \pm 5.78$ & $<0.001^{* *}$ \\
\hline
\end{tabular}

\#Paired ' $t$ ' test; ${ }^{* *} \mathrm{p}<0.001$; Highly significant

Table 9: Table Showing Comparison of Improvement in Vas Score Between Two Groups.

\begin{tabular}{|c|c|c|c|c|c|}
\hline \multirow{2}{*}{ Time } & \multicolumn{2}{|c|}{ Group 1 } & \multicolumn{2}{c|}{ Group 2 } & \multirow{2}{*}{ P VALUE } \\
\cline { 2 - 5 } & Mean & SD & Mean & 3.07 & $<0.001^{* *}$ \\
\hline Baseline to 3 months & 78.33 & 5.47 & 90.17 & 6.35 & 0.124 \\
\hline Baseline to 6 months & 76.50 & 6.04 & 79.00 & 5.78 & 0.258 \\
\hline Baseline to 12 months & 58.83 & 5.52 & 60.50 & \\
\hline
\end{tabular}

\#Unpaired ' $\mathrm{t}$ ' test; ** $\mathrm{p}<0.001$; Highly significant

\section{Results as Per Vas Score Comparison}

Results were compared between baseline and at 3, 6 and 12 months follow up.

Results evaluation as per VAS Scale improvement
- $\quad$ Excellent $>80 \%$ Improvement

- Good 60-80\% Improvement

- Fair 40-60\% Improvement

- $\quad$ Poor < 40\% Improvement (Tables 10-12) (Graphs 8-10) 


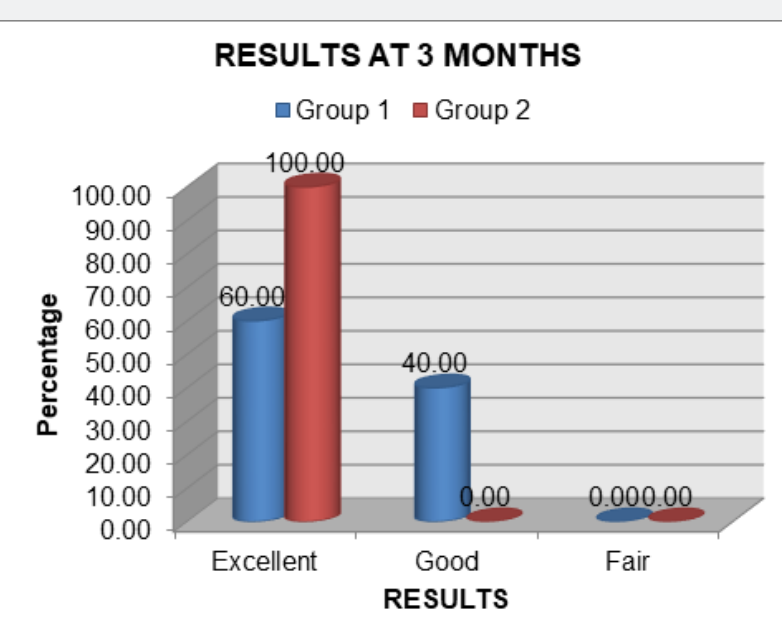

Graph 8

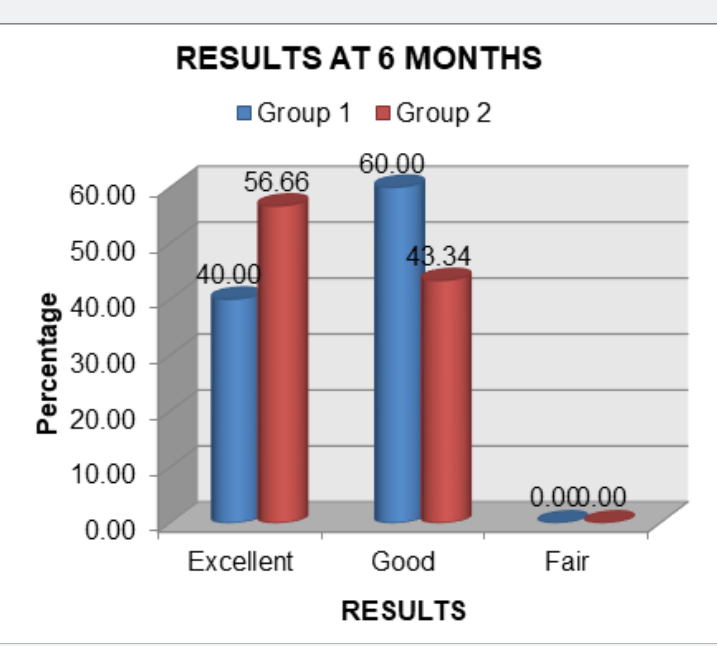

Graph 9

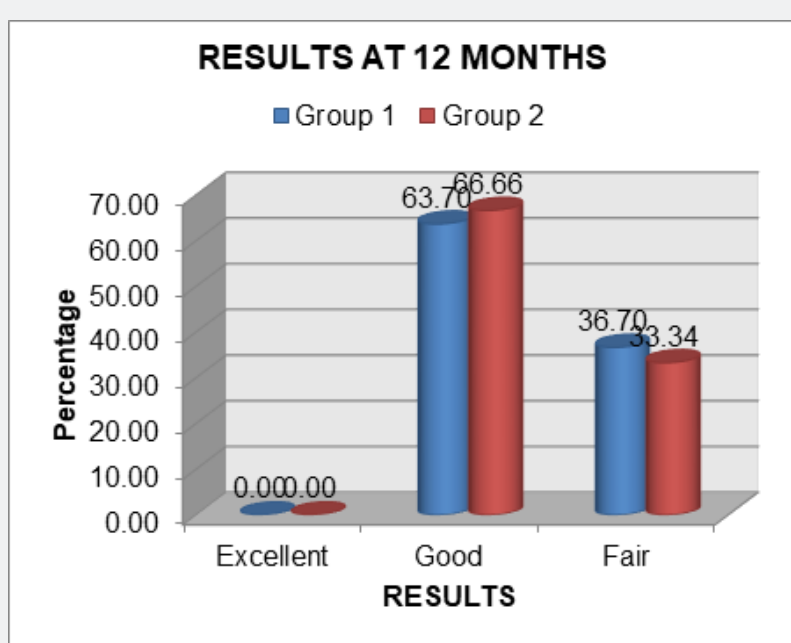

Graph 10 


\section{Orthopedics and Rheumatology Open Access Journal (OROAJ)}

Table 10: Results at 3 months.

\begin{tabular}{|c|c|c|c|c|}
\hline \multirow{2}{*}{ Results } & \multicolumn{2}{|c|}{ Group 1 } & \multicolumn{2}{c|}{ Group 2 } \\
\cline { 2 - 5 } & $\mathbf{N}$ & $\mathbf{\%}$ & $\mathbf{N}$ & $\mathbf{\%}$ \\
\hline Excellent & 18 & 60.0 & 30 & 100.0 \\
\hline Good & 12 & 40.0 & - & - \\
\hline Fair & - & - & - & - \\
\hline Total & 30 & 100.0 & 30 & 100.0 \\
\hline
\end{tabular}

Table 11: Results at 6 months.

\begin{tabular}{|c|c|c|c|c|}
\hline \multirow{2}{*}{ Results } & \multicolumn{2}{|c|}{ Group 1 } & \multicolumn{2}{c|}{ Group 2 } \\
\cline { 2 - 5 } & N & \% & N & \% \\
\hline Excellent & 12 & 40.0 & 17 & 56.66 \\
\hline Good & 18 & 60.0 & 13 & 43.34 \\
\hline Fair & - & - & - & - \\
\hline Total & 30 & 100.0 & 30 & 100.0 \\
\hline
\end{tabular}

Table 12: Results at 12 months.

\begin{tabular}{|c|c|c|c|c|}
\hline \multirow{2}{*}{ Results } & \multicolumn{2}{|c|}{ Group 1 } & Group 2 \\
\cline { 2 - 5 } & $\mathbf{N}$ & $\mathbf{0}$ & $\mathbf{0}$ \\
\hline Excellent & - & - & 20 & 66.66 \\
\hline Good & 19 & 63.70 & 10 & 33.34 \\
\hline Fair & 11 & 36.7 & 30 & 100.0 \\
\hline Total & 30 & 100.0 & & \% \\
\hline
\end{tabular}

\section{KO0S Scores}

Before injecting the PRP and at 3months, 6 months and 12 months interval patients were assessed according to KOOS SCORE regarding pain, stiffness, and physical function (daily living), quality of life, sports activities, symptoms. More the KOOS score better was the pain relief. The baseline mean KOOS score was 00.00 with standard deviation of 00.00 .

In Group 1 at 3 month, KOOS score ranged from 55 to 74 and mean score of 64.30 and standard deviation of 5.11. Improvement in KOOS score at 3 months from baseline was calculated which came out to be mean score of 64.30 and standard deviation of 5.11. In Group 2 at 3-month KOOS score ranged from 79 to 93 and mean score of 85.87 and standard deviation of 3.91. Improvement in KOOS score at 3 months from baseline was calculated which came out to be mean score of 85.87 and standard deviation of 3.91. In Group 1 at 6-month KOOS score ranged from 50 to 67 and mean score of 57.37 and standard deviation of 4.81. Improvement in KOOS score at 6 months from baseline was calculated which came out to be mean score of 57.37 and standard deviation of 4.81 .

In Group 2 at 6-month KOOS score ranged from 49 to 68 and mean score of 58.13 and standard deviation of 4.98. Improvement in KOOS score at 6 months from baseline was calculated which came out to be mean score of 58.13 and standard deviation of 4.98. In Group 1 at 12 -month KOOS score ranged from 32 to 50 and mean score of 40.97 and standard deviation of 4.50. Improvement in KOOS score at 12 months from baseline was calculated which came out to be mean score of 40.97 and standard deviation of 4.50 . In Group 2 at 12-month KOOS score ranged from 32 to 53 and mean score of 42.77 and standard deviation of 5.16. Improvement in KOOS score at 12 months from baseline was calculated which came out to be mean score of 42.77 and standard deviation of 5.16 (Tables 13-15) (Graphs 11-13).

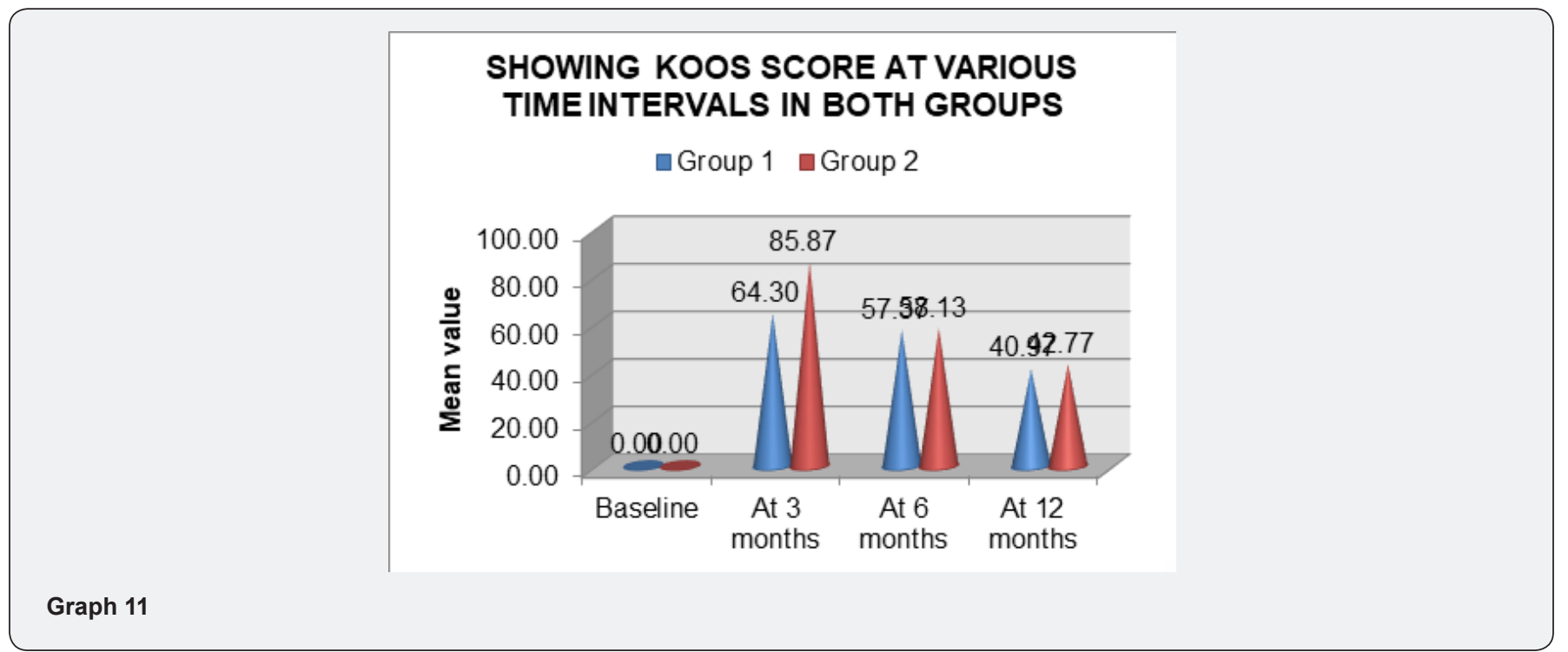



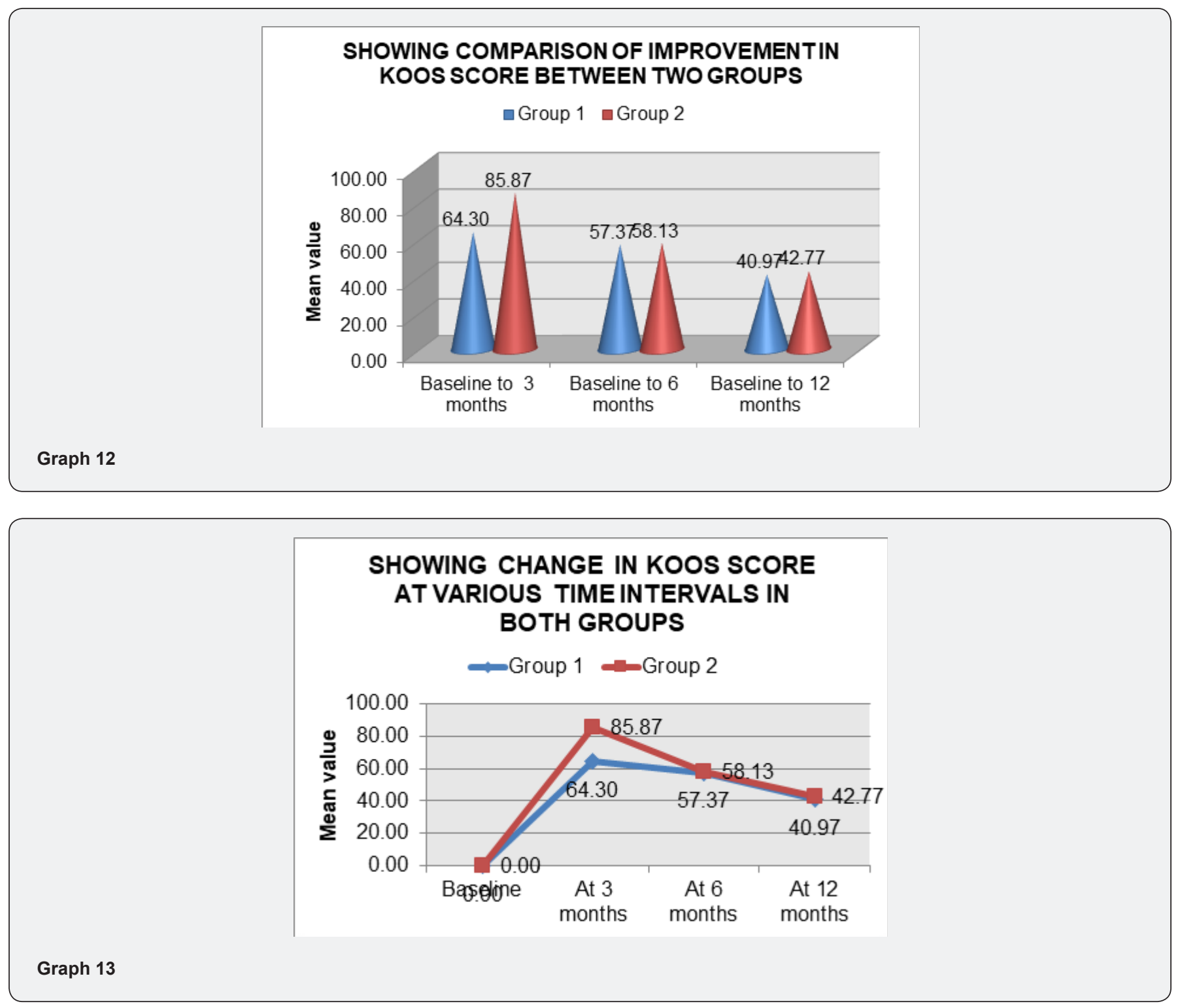

Table 13: Showing Koos Score at Various Time Intervals in Both Groups.

\begin{tabular}{|c|c|c|c|c|c|c|c|}
\hline \multirow{2}{*}{ Time } & \multicolumn{3}{|c|}{ Group 1 } & \multicolumn{3}{c|}{ Group 2 $^{*}$ P value ${ }^{\#}$} \\
\cline { 2 - 8 } & Range & Mean & SD & Range & Mean & SD & - \\
\hline Baseline & $0-0$ & 0.00 & 0.00 & $0-0$ & 00.00 & 0.00 & 3.91 \\
\hline At 3 months & $55-74$ & 64.30 & 5.11 & $79-93$ & 85.87 & $<0.001^{* *}$ \\
\hline At 6 months & $50-67$ & 57.37 & 4.81 & $49-68$ & 58.13 & 4.98 & 0.547 \\
\hline At 12 months & $32-50$ & 40.97 & 4.50 & $32-53$ & 42.77 & 5.16 & 0.156 \\
\hline
\end{tabular}

\#Unpaired 't' test; ** $\mathrm{p}<0.001$; Highly significant

Table 14: MEAN Table Showing Comparison of Improvement in Koos Score Between Two Groups MEAN (Improvement from baseline)

\begin{tabular}{|c|c|c|c|c|c|}
\hline \multirow{2}{*}{ Time } & \multicolumn{2}{|c|}{ Group 1 } & \multicolumn{2}{c|}{ Group 2 } & \multirow{2}{*}{ P VALUE $^{\#}$} \\
\cline { 2 - 5 } & Mean & SD & Mean & 3.91 & $<0.001^{* *}$ \\
\hline Baseline to 3 months & 64.30 & 5.11 & 85.87 & 4.98 & 0.547 \\
\hline Baseline to 6 months & 57.37 & 4.81 & 58.13 & 5.16 & 0.156 \\
\hline Baseline to 12 months & 40.97 & 4.50 & 42.77 & \\
\hline
\end{tabular}

\#Unpaired ' $t$ ' test; ** $p<0.001$; Highly significant 


\section{Orthopedics and Rheumatology Open Access Journal (OROAJ)}

Table 15: Table Showing Change in Koos Score at Various Time Intervals.

\begin{tabular}{|c|c|c|c|c|c|c|c|c|}
\hline \multirow{2}{*}{ Time } & \multicolumn{9}{|c|}{ Group 1 } & \multicolumn{2}{c|}{ Group 2 $^{-1}$} \\
\cline { 2 - 8 } & Mean & SD & Improvement & P value $^{\#}$ & Mean & SD & Improvement $^{\text {P value }}$ \\
\hline Baseline & 0.00 & 0.00 & - & - & 0.00 & 0.00 & - \\
\hline At 3 months & 64.30 & 5.11 & $64.30 \pm 5.11$ & $<0.001^{* *}$ & 85.87 & 3.91 & $85.87 \pm 3.91$ & $<0.001^{* *}$ \\
\hline At 6 months & 57.37 & 4.81 & $57.37 \pm 4.81$ & $<0.001^{* *}$ & 58.13 & 4.98 & $58.13 \pm 4.98$ & $<0.001^{* *}$ \\
\hline At 12 months & 40.97 & 4.50 & $40.97 \pm 4.50$ & $<0.001^{* *}$ & 42.77 & 5.16 & $42.77 \pm 5.16$ & $<0.001^{* *}$ \\
\hline
\end{tabular}

\#Paired ' $t$ ' test; ${ }^{* *} \mathrm{p}<0.001$; Highly significant

\section{Complications}

In none of the cases any deep or superficial infection was observed. 14 patients experienced heaviness in knee after the injection of PRP which disappeared within 2-3 hours spontaneously. Aggravation of pain was observed for 24 hours in 7 patients.

\section{Discussion}

The present study was undertaken with the chief aim to determine the effect of intra-articular injection of platelet-rich plasma (prp) in symptomatic patients with knee osteoarthtitis and to educate the patients regarding importance of early intervention. The present study included 60 patients with symptomatic knee Osteoarthritis of grade 1-3 as per Kellgren-Lawrence classification based on x-ray findings. The standard radiographic evaluation will include a standing AP and lateral view of the knees.

Group 1 - 30 patients will be given 1 intra-articular injection of Autologous PRP and followed up for a period of 1year.

Group 2 - 30 will be given 2 intra-articular injection of Autologous PRP 2 weeks apart and followed up for a period of 1year.

\section{AGE}

In the present study maximum patients were in the age group of 5 th decade. The youngest patient in Group1 of this study was 40 years and oldest was of 60 years and in Group 2 was 42 and 59 years. Average age of Group 1 was 51.7 years and of Group 2 was 50 and 33 years. The incidence increases with age, and by age 65 approximately $80 \%$ have radiographic evidence of $0{ }^{69}$ The peak performance of an individual is around age of 30 years and after that physical decline starts gradually. Around the age of 50 years, the decline becomes fast and as such the degenerative changes start appearing symptomatically.

\section{SEX}

In our study, females outnumbered males in presenting with pain due to knee OA both in Group 1 and 2.18 (60\%) patients were female and 12 (40\%) patients were male in Group 1 and 17
(56.7\%) patients were female and 13 (43.3\%) were male in Group 2. Female to male ratio was 6:4 in Group 1 and 1.3:1 in Group 2. The most important modifiable risk factor of $\mathrm{OA}$ is obesity and having a BMI $>25$ significantly increases the risk of symptomatic knee OA in women. Female predominance is attributed to the hormonal changes due to menopause resulting in early onset of degeneration and the lesser bone mass. In India, the scenario is worsened for females because of social habits of squatting during worshipping, cleaning, and mopping of household etc.

\section{Side Involved}

In the present study, $46.7 \%$ (14) of patients had left knee involvement and 53.3\%(16) of patients had right knee involvement. Ratio of side of limb involvement from left to right was 7:8.

\section{Kellgren-Lawrence Grading}

In the present study $6(20 \%)$ patients of grade $1,16(53.3 \%)$ patients of grade 2 and $8(26.7 \%)$ patients of grade 3 were included in study. The predominance of grade 2 is attributed to the fact that in grade 1 the symptoms are very mild and the patient is not bothered much to consult a specialist and usually household remedies are tried by these people, once these remedies fail or they progress to grade 2 and pain is not relieved, then they consult the specialist for treatment.

\section{VAS score}

In our study baseline VAS score of the patient was taken at 100 at the time of presentation to the outpatient department. The mean VAS score at 3 months follow up in Group 1 and Group 2 was 21.67 and 9.83 respectively. Improvement in VAS score at 3 months from baseline in Group 1 and Group 2 was 78.33 and 90.17 respectively. The comparative three-month reduction in mean VAS scores from baseline was found to be statistically highly significant with $\mathbf{p}$ value $<0.001$ in both groups. Improvement in VAS score at 3 months comparing between both the groups was found to be highly statistically significant with $p$ value $<0.001$. At follow up, 18 patients had excellent improvement in VAS score and 12 patients had good improvement in VAS score in group 1 , while in group 2 all patients had excellent improvement. 
At 6 months follow up the mean VAS score in Group 1 and Group 2 was 23.50 and 21.00. Improvement in VAS score from baseline in Group 1 and Group 2 was 76.50 and 79.00. The comparative sixmonth reduction in mean VAS scores from baseline was found to be statistically highly significant with $\mathbf{p}$ value $<0.001$ in both groups. Improvement in VAS score at 6 months comparing between both the groups was found to be statistically non-significant with $p$ value 0.124 . At follow up, 12 patients had excellent improvement in VAS score and 18 patients had good improvement in VAS score in group 1, while in group 217 patients had excellent and 13 had good improvement. At final 12 months follow up the mean VAS score in Group 1 and Group 2 was 41.17 and 39.50. Improvement in VAS score from baseline in Group 1 and Group 2 was 658.83 and 60.50. The comparative twelve-month reduction in mean VAS scores from baseline was found to be statistically significant with p value $<0.001 q$ in both groups. Improvement in VAS score at 12 months comparing between both the groups was found to be statistically non-significant with p value 0.258 .

At follow up, 19 patients reported good improvement in VAS score and 11 of them reported fair improvement in VAS score, while in group 20 had good and 10 had fair improvement. Similar sustained pain relief was observed in our study also which showed sustained improvement till 6 months in all the 30 patients, after that patients started experiencing pain but still the results were statistically significant from the baseline. Upto 6 months none of the patient was in fair or poor group but at 12 months follow up 9 patients were in fair group which showed patients started experiencing pain as efficacy of the procedure started decreasing after 6 months.

\section{Ko0S Score}

The baseline mean KOOS score was 00.00 with standard deviation of 0.00 . The mean KOOS score at 3 months follow up in Group 1 and Group 2 was 64.30 and 85.87. Improvement in KOOS score at 3 months from baseline in Group1 and Group2 was 64.30 and 85.87 . The comparative 3 month change in mean KOOS scores from baseline was found to be statistically highly significant with p value $<0.001$ Improvement in KOOS score at 3 months comparing between both the groups was found to be highly statistically significant with $\mathrm{p}$ value $<0.001$

The mean KOOS score at 6 months follow up in Group 1 and Group 2 was 57.37 and 58.13. Improvement in KOOS score at 6 months from baseline in Group1 and Group2 was 57.37 and 58.13. The comparative 6 month change in mean KOOS scores from baseline was found to be statistically significant with $\mathbf{p}$ value $<0.001$. Improvement in KOOS score at 6 months comparing between both the groups was found to be statistically nonsignificant with $\mathrm{p}$ value 0.547

The mean KOOS score at 12 months follow up in Group 1 and Group 2 was 40.97 and 42.77. Improvement in KOOS score at 12 months from baseline in Group1 and Group2 was 40.97 and
42.77. The comparative 12 month change in mean KOOS scores from baseline was found to be statistically significant with $\mathbf{p}$ value $<0.001$. Improvement in KOOS score at 12 months comparing between both the groups was found to be statistically nonsignificant with $p$ value 0.156

\section{Complications}

No major complication such as deep infection, muscle atrophy, deep vein thrombosis, fever, hematoma, tissue hypertrophy, adhesion formation, or other major adverse events occurred among patients. In our study 14 patients experienced heaviness in knee and 7 patients experienced aggravation of pain for first 24 hours which resolved spontaneously. This is attributed to the sudden increase in the volume of intracapsular contents leading to capsular stretch and hence pain. Once some absorption occurs the stretch pain settles down. Spakova' $\mathrm{T}$ et al in their study documented temporary mild worsening of pain in the knee joint after application of PRP in six cases out of 60 , which was spontaneously resolved after 2 days. Pain can also be produced due to the quality of PrP injected. If number of leucocytes and few RBC are more in the injected material, then the inflammation cascade initiated will be more and as such can initiate the pain.

\section{Conclusion}

We conclude that intra- articular injection of Autologous PrP is an acceptable method to relieve pain in first three stages of O.A. Due to Autologous nature of PRP there are very less chances of complication, thus we recommended intra-articular PRP injection is a simple, minimally invasive, safe and effective method which can be used for the treatment of osteoarthritis of knee. 2 injections of PRP given at 2 weeks apart gives better relief from pain based on VAS and KOOS score at 3 months follow up but data was not significant comparing single vs two injections of prp at follow up of 6 months and 12 months.

\section{References}

1. Hunter W (1995) Of the structure and disease of articulating cartilages. 1743. Clin Orthop Relat Res 317(317): 3-6.

2. Kathleen DW (2000) American College of Rheumatology Subcommittee on Osteoarthritis Guidelines. Recommendations for the medical management of osteoarthritis of the hip and knee: 2000 update. Arthritis Rheum 43(9): 1905-1915.

3. Felson DT, Lawrence RC, Dieppe PA, Hirsch R, Helmick CG, et al. (2000) Osteoarthritis: new insights. Part 1: the disease and its risk factors. Ann Intern Med 133(8): 635-646.

4. Dieppe PA, Lohmander LS (2005) Pathogenesis and management of pain in osteoarthritis. Lancet 365(9463): 965-973.

5. Widuchowski W, Widuchowski J, Trzaska T (2007) Articular cartilage defects: study of 25,124 knee arthroscopies. Knee 14(3): 177-182.

6. Barten DJ, Swinkels LC, Dorsman SA, Dekker J, Veenhof C, (2015) Treatment of hip/knee osteoarthritis in Dutch general practice and physical therapy practice: an observational study. BMC Fam Pract 16(1): 75 . 
7. Silverwood V, Blagojevic-Bucknall M, Jinks C, Jordan JL, Protheroe J, et al. (2015) Current evidence on risk factors for knee osteoarthritis in older adults: a systematic review and meta-analysis. Osteoarthritis Cartilage 23(4): 507-515.

8. Patel S, Dhillon MS, Aggarwal S, Marwaha N, Jain A (2013) Treatment with platelet-rich plasma is more effective than placebo for knee osteoarthritis: a prospective, double-blind, randomized trial. Am J Sports Med 41(2): 356-364.

9. Bland JH (1983) The reversibility of osteoarthritis: a review. Am J Med 74(6 6A): 16-26.
10. Pelletier JP, DiBattista JA, Roughley P, McCollum R, Martel-Pelletier J (1993) Cytokines and inflammation in cartilage degradation. Rheum Dis Clin North Am 19(3): 545-568.

11. Kellgren JH, Lawrence JS (1957) Radiological assessment of osteoarthrosis. Ann Rheum Dis 16(4): 494-502.

12. Wei X, Yang X, Han ZP, Qu FF, Shao L, et al. (2013) Mesenchymal stem cells: a new trend for cell therapy. Acta Pharmacol Sin 34(6): 747-754.

\section{Your next submission with Juniper Publishers will reach you the below assets}

- Quality Editorial service

- Swift Peer Review

- Reprints availability

- E-prints Service

- Manuscript Podcast for convenient understanding

- Global attainment for your research

- Manuscript accessibility in different formats ( Pdf, E-pub, Full Text, Audio)

- Unceasing customer service

Track the below URL for one-step submission https://juniperpublishers.com/online-submission.php 